\section{Carta de risco de inundação a partir de modelos SRTM na área urbana de Pau dos Ferros - RN}

\begin{abstract}
Resumo: Drenagens da bacia hidrográfica do Rio Apodi atravessam a área urbana da cidade de Pau dos Ferros - RN e são responsáveis por inundações durante o período chuvoso, em áreas indevidamente ocupadas. O ineficiente sistema da drenagem urbana, aliado ao processo de perenização do rio pelo projeto de integração da bacia hidrográfica do São Francisco com as Bacias do Nordeste Setentrional poderão contribuir para a ampliação das áreas de inundação na cidade de Pau dos Ferros - RN. Neste sentido, este trabalho objetivou identificar estas áreas de risco na cidade de Pau dos Ferros. Para o mapeamento, utilizou-se imagem orbital do sensor HRC do satélite CBERS 2B e modelo SRTM. As áreas de risco de inundação foram demarcadas mediante fatiamento de 20 em 20 metros da imagem SRTM, utilizando o SIG SPRING 5.1. Os primeiros resultados permitiram visualizar que alguns bairros ao longo do rio Apodi estão susceptíveis a ocorrências de inundações de baixo a alto grau, enquanto que nos bairros próximos ao riacho Cajazeiras as inundações serão de baixo grau devido à altimetria mais elevada e o menor volume d'água.
\end{abstract}

\section{Flood Risk Map from SRTM Images in Urban Area of Pau dos Ferros - RN/Brazil}

\begin{abstract}
Drainages of the Apodi River hydrographic basin cross the urban area of Pau dos Ferros City $-\mathrm{RN}$ and are responsible for floods during the rainy season, in unduly occupied areas. The inefficient system of urban drainage, allied to the perennial process of this river by the integration project from San Francisco River hydrographic basin with the brazilian northern Northeast basins may enlarge the flood areas. This work aims to identify flood risk areas in the Pau dos Ferros city. Sensor HRC image of CBERS 2B satellite of 2008 and Shuttle Radar Topography Mission model were used for mapping. Then, the flood risk areas were delimited by isolines extraction tool for slicing generation every 20 meters obtained from image Shuttle Radar Topography Mission in SPRING 5.1 GIS. The results allow visualizing that some neighborhoods along the Apodi River are susceptible to more flooding events from low to high grade, while in neighborhoods of the Cajazeiras rivulet the floods will be of low grade because of the higher altimetry and less water volume.
\end{abstract}

Franklin Roberto da Costa

Raquel Franco de Souza

Lima**

Sebastião Milton Pinheiro da Silva***

* Professor Adjunto I do departamento de Geografia da Universidade do Estado do Rio Grande do Norte

** Professora associada III da Universidade Federal do Rio Grande do Norte

***Professor Adjunto na Universidade Federal do Rio Grande do Norte

Palavras-chave:
$\begin{aligned} & \text { Spring/INPE, Imagens } \\ & \text { orbitais; } \\ & \text { nordestino. }\end{aligned}$

Key-Words:

Spring/INPE; orbital images; northern semiarid. 


\section{Introdução}

O processo de ocupação das cidades começou próximo às margens dos rios. Este processo se deu pela necessidade de utilização do rio como fluxo de pessoas e mercadorias e pela proximidade das melhores terras agrícolas. Com o avanço tecnológico, a cidade passou a ser o espaço da produção econômica e social, seja pelo comércio ascendente, como também pelos serviços básicos, tais como saúde, educação e lazer. Neste caso, os reflexos gerados por este avanço refletiram (e ainda refletem) sobre a infraestrutura urbana, ocasionando impactos sociais, econômicos e ambientais em função do uso inadequado do meio físico no qual se instalaram (SATHLER, 2009. PEDRON ET AL, 2006. GROSTEIN, 2001).

No caso das áreas ribeirinhas brasileiras, pode-se dizer que o processo de ocupação vem se realizando de forma contínua, tendo como justificativa a realização, com custo menor, da captação das águas para o consumo humano, como também para o escoamento dos resíduos produzidos pelas indústrias, comércios e residências (ZHOURI e OLIVEIRA, 2006. ANTUNES e BARROS, 2009. GONÇALVES, 2007)

Segundo Tucci (2004), a falta de um planejamento urbano coerente com as normas de ocupação do solo pode ser consideradoum dos responsáveis pelas inundações existentes na atualidade, pois este planejamento vem se realizando no Brasil apenas nas partes das cidades ocupadas pela população de média e alta renda, enquanto que nas áreas com população de baixa renda e de periferia, o processo de ocupação se dá de forma irregular ou clandestina.

No município de Pau dos Ferros - RN a situação não é diferente. Localizado na parte oeste do Estado do Rio Grande do Norte, o município é considerado um dos Pólos Regionais do Estado, por agregar os principais serviços públicos prestados pelo Estado na Região denominada Alto Oeste Potiguar. A implantação destes serviços gerou como consequência, um processo de urbanização crescente e desordenado, fazendo com que o fluxo migratório seguisse o caminho em busca de uma melhor qualidade de vida na cidade.

A inundação em Pau dos Ferros aparece neste cenário como um dos impactos decorrentes deste processo de ocupação, às margens do Rio Apodi e em um dos seus afluentes, o riacho Cajazeiras, os quais circundam a cidade de Pau dos Ferros, à leste e à oeste respectivamente. Todos os anos, durante o período chuvoso na Região, que ocorre, em média, entre os meses de fevereiro a maio, onde parte do centro urbano, assim como bairros periféricos, sofrem com a inundação decorrida do transbordamento das águas do rio Apodi e do seu afluente Cajazeiras, a partir do transbordamento do açude 25 de Março. Como consequência, casas são invadidas pela água, parte da população fica desabrigada, e há dificuldade de acesso em determinados bairros, pelo alagamento das vias rodoviárias.

Tendo em vista que as áreas de inundação não estão plenamente definidas, o presente trabalho objetiva avaliar os riscos de inundação na cidade de Pau dos Ferros, localizada na Região Oeste Potiguar. O município será um dos contemplados pela integração da bacia hidrográfica do São Francisco com as Bacias do Nordeste Setentrional (Integração da Bacia do São Francisco) e terá como resultado a perenização do Rio Apodi que, atualmente, mesmo sendo intermitente, é responsável pelas inundações no centro urbano de Pau dos Ferros, decorrentes das chuvas na região. Entende-se que, a partir da transposição das águas do Rio São Francisco, haverá um aumento nas áreas inundáveis na cidade a partir da sua implantação, pois o mesmo perenizará o Rio Apodi, fazendo com que o mesmo transborde com uma quantidade de chuvas menor que a habitual para que ocorra o transbordamento, a partir de $1.000 \mathrm{~mm}$ de chuvas anuais.

Para mensurar os riscos de inundação na cidade foram produzidos mapas temáticos com uso do Sistema de Informação Geográfica - SIG/ Sistema para Processamento de Informações Georreferenciadas - SPRING 5.1, além de pesquisa de campo, o uso do modelo Shuttle Radar Topography Mission - SRTM e imagens aéreas e de satélite. A metodologia

Geografia Ensino \& Pesquisa, v. 17, n.2 p. 182-198, maio/ago. 2013

Costa, F. R.; Lima, R. F. S.; Silva. S. P. P

ISSN 2236-4994 
adotada pode ser aplicada em outras cidades com características semelhantes à área em estudo como ferramenta de auxílio para a gestão urbana e ambiental da cidade de Pau dos Ferros $\mathrm{RN}$.

\section{Inundações - Principais Conceitos}

Dentro dos problemas ambientais existentes nos municípios brasileiros, a inundação aparece neste cenário como um dos mais estudados, por ser um dos mais ocorrentes nas cidades brasileiras. Segundo ISDR (2002), inundações e enchentes são problemas geoambientais derivados de fenômenos ou perigos naturais de caráter hidrometereológico ou hidrológico, ou seja, aqueles de natureza atmosférica, hidrológica ou oceanográfica.

Para Pereira e Silva (2007) a inundação se caracteriza pelo excesso do volume de água que não consegue ser drenado e ocupa a várzea inundável de acordo com a topografia das áreas próximas aos rios, em função dos processos climáticos locais e regionais.

Segundo Rocha (1995), para que aconteça uma inundação é necessário haver uma cheia que provoque o transbordamento do leito normal, ou leito menor do rio. Este transbordamento (ou seja, inundação) ocorre a partir de condições meteorológicas e hidrológicas e seus impactos são classificados em naturais e artificiais (SILVA e BARBOSA, 2007).

As condições naturais são caracterizadas pelos condicionantes físicos que constituem uma bacia, tais como o relevo, o tipo de precipitação, a cobertura vegetal e a sua capacidade de drenagem. Neste caso, a interferência humana não influi na ocorrência das inundações (TUCCI, 2004).

Ainda, segundo o autor, nas condições artificiais, o homem é agente principal para a ocorrência de inundações, já que seus produtos (obras hidráulicas, desmatamento, uso agrícola, urbanização desordenada) geram como consequência o aumento da vazão máxima e do escoamento superficial, acelerando assim a ocorrência das inundações.

A combinação destes condicionantes (naturais e artificiais) é responsável pelas principais inundações no Brasil, principalmente nas áreas urbanas. Segundo Pereira e Silva (2007), elas ocorrem, principalmente, devido ao desmatamento, à pavimentação do solo, às construções, aos movimentos de terra, e aos aterros de reservatórios e de curso d'água, aumentando a frequência e magnitude das enchentes, somado ao processo natural no qual o volume da água do rio transborda até o leito maior da planície de inundação, atingindo as habitações que ocupam áreas inapropriadas à ocupação humana.

\footnotetext{
A remoção do solo e/ou da cobertura vegetal, a emissão de resíduos sólidos e a impermeabilização das superfícies são responsáveis pelo aumento das vazões máximas dos canais e condutos que escoam as águas precipitadas nas cidades. O resultado direto destes fatores é o transbordamento das águas. A lavagem das ruas, o transporte de material sólido e as ligações clandestinas de esgoto cloacal e pluvial realizados pelas águas do transbordamento deterioram a qualidade das águas superficiais e subterrâneas (COSTA, 2010).
}

Geografia Ensino \& Pesquisa, v. 17, n. 2 p. 182-198, maio/ago. 2013

Carta de risco de inundação a partir de modelos srtm na área urbana de pau dos Ferros - RN

184 I ISSN 2236-4994
As cidades brasileiras encontram-se inseridas neste processo, uma vez que a forma de ocupação desordenada criou, ao longo de décadas, cenários de desastres ambientais e sociais que se repetem constantemente, sempre que ocorre uma precipitação mais intensa. De acordo com a Agência Nacional das Águas - ANA (2009), houve um número expressivo de municípios brasileiros que decretaram Situação de Emergência - SE para o ano de 2008, como pode ser visto na figura 01. O mapa representa apenas os municípios que declararam situação de emergência por causa das enchentes, não retratando a realidade das várias cidades brasileiras, que historicamente possuem seu processo de urbanização realizado nas proximidades dos rios. 
Figura 01- Sedes municipais com decretação de SE (Situação de Emergência) por enchentes em 2008.

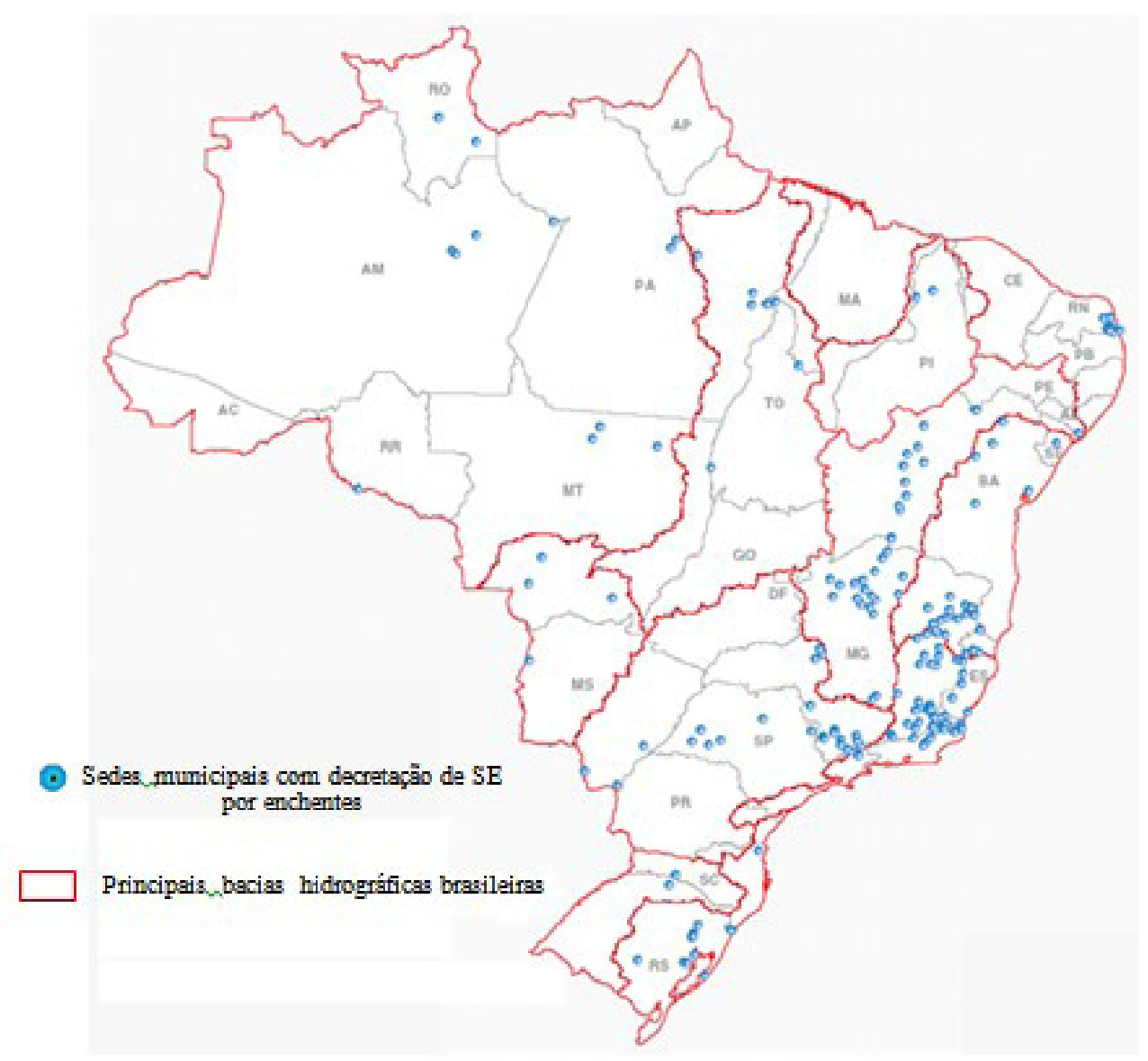

Fonte: ANA, 2009

Tucci (2005) afirma que este processo é agravado nas regiões metropolitanas, pois estas deixaram de crescer nas cidades polos, e se expandem nas periferias, nas proximidades das zonas ribeirinhas dos rios, tanto a montante quanto a jusante.

Um dos fatores que influenciam no aumento das inundações nas cidades brasileiras é a sua forma de ocupação, pois seu processo se dá de forma irregular, geralmente ocupando áreas susceptíveis às inundações.

\section{Alguns trabalhos realizados no Brasil}

Os problemas ambientais relacionados a inundações no Brasil estão elencados, ao lado da seca e da poluição, como um dos assuntos mais abordados nos dias atuais. Na mídia e no meio acadêmico, as discussões sobre tal fenômeno aparecem em destaque, demonstrando os problemas que a falta de planejamento por parte das esferas políticas em todos os seus níveis (federal, estadual e municipal) geram para a sociedade, podendo-se destacar cenas de enchentes decorrentes, principalmente nas áreas urbanas, ocasionadas pelo assoreamento do leito dos rios, pela impermeabilização das áreas de infiltração na bacia de drenagem ou por fatores climáticos.

Geografia Ensino \& Pesquisa, v. 17, n. 2 p. $182-198$, maio/ago. 2013

Costa, F. R.; Lima, R. F. S.; Silva. S. P. P

ISSN 2236-4994 
avanço das águas na cidade, assim como na contagem (em tempo real) das mortes e no número dedesabrigados, ocasionados direta ou indiretamente, pelas inundações (enchentes) ocorridas nestes locais. Na tragédia em Santa Catarina, no ano de 2008, foi criado um site pelo Governo do Estado (www.desastre.sc.gov.br) com o objetivo de repassar informações a respeito dos fatos decorrentes das enchentes ocorridas no final do ano nos municípios catarinenses, desde a tragédia direta como também as doações e ações realizadas pelo Estado e pelos municípios atingidos.

No meio acadêmico, existem trabalhos com o tema inundação para várias cidades em todo o país, onde são colocados problemas equivalentes com diferentes enfoques, tais como: Pereira Filho et al. (2004), que apresentam uma análise hidrometeorológica das enchentes na Região Metropolitana de São Paulo; Silveira e Kobiyama (2007), onde trabalharam o gerenciamento de inundações em Blumenau - SC a partir da busca de registros documentais de ocorrências de inundações neste município entre 1851 e 2007; Briguenti et al. (2007) procuraram analisar a ocorrência e a distribuição espacial dos riscos hidrogeomorfológicos em unidades geossistêmicas mapeadas na bacia hidrográfica do ribeirão das Anhumas, Campinas/ SP; Silva et al. (2008) analisaram a variação temporal da precipitação na bacia do rio Mundaú (Alagoas e Pernambuco) e do Rio Paraíba (Paraíba) entre os anos de 1974 e 1983 para entender as anomalias relacionadas às precipitações que causaram inundações durante este período na região.

Houve um avanço considerável nas pesquisas e discussões a respeito da avaliação de inundações em escala local, sendo o Estado de São Paulo aquele que possui a maior quantidade de estudos científicos no país. Percebe-se também que grande parte dos trabalhos levou em conta a relação espaço - tempo para entender como funciona a dinâmica das inundações e, a partir desta avaliação, procurar meios de amenizar os desastres que, porventura, possam ocorrer em períodos posteriores.

Outra característica intrínseca aos trabalhos existentes no país é a relação das inundações com a expansão das áreas urbanas, principalmente nas médias e grandes cidades brasileiras. Como os riscos ambientais (mais especificamente os riscos de inundação) estão relacionados ao binômio natureza-sociedade, o problema do avanço da urbanização sem critérios claros de ocupação, faz com que se amplie o número de cidades com riscos maiores de impactos relacionados à inundação.

Esta constatação é reforçada por Tucci e Bertoni (2003), que afirmam que o processo de urbanização tem gerado impactos que deterioram a qualidade de vida da população, através do aumento da frequência e do nível das inundações, redução da qualidade de água e aumento de materiais sólidos no escoamento pluvial.

Um dos instrumentos utilizados para a detecção destes impactos está no uso de Geotecnologias, sendo este um importante instrumento de auxílio à identificação espacial de fenômenos socioeconômicos e ambientais existentes na superfície terrestre. Atualmente, no cenário mundial, há um número considerável de softwares destinados a tal função. E estes vêm sendo utilizados com frequência para os estudos relacionados à inundação no país.

Como exemplo de aplicação desta ferramenta cita-se a dissertação de mestrado de Enomoto (2004), que teve como objetivo a elaboração de mapas de inundação para a bacia do rio Palmital, localizada na Região Metropolitana de Curitiba, nos municípios de Colombo e Pinhais. O autor utilizou o software ArcView para a confecção dos mapas.

Jesus (2007) analisa a viabilidade de aplicação de imagens do sensor CCD do satélite CBERS 2, associadas a dados SRTM e levantamentos altimétricos com o Sistema de Posicionamento Global - GPS no desenvolvimento de um SIG para a simulação de manchas de inundação e permeabilidade do solo na área urbana da cidade de Jacobina-BA.

O agrupamento de dados também é marca inerente das geotecnologias, através da compilação de informações geográficas. Neves (2005) utilizou imagens de satélite JERS-1

Carta de risco de inundação a partir de modelos srtm na área urbana de pau dos Ferros - RN

186 I ISSN 2236-4994 
na faixa de microondas do tipo SAR, para os anos de 1995 e 1996 para realizar análises conjuntamente com informações de saúde do banco de dados DATASUS em um sistema de informações geográficas. Como resultado observou-se relação significativa entre doenças hídricas e áreas inundáveis, caracterizadas por dados fluviométricos e mapeadas por sensoriamento remoto.

\section{Geotecnologias - principais conceitos}

A coleta de informações sobre a distribuição geográfica de recursos minerais, propriedades, animais e plantas sempre foi parte importante das sociedades organizadas. Até recentemente, no entanto, isto era feito apenas em documentos e mapas em papel; impedindo uma análise que combinasse diversos mapas e dados. Com o desenvolvimento da tecnologia da informação, tornou-se possível armazenar, representar, integrar e espacializar mapas e dados, abrindo espaço para o surgimento das ferramentas de geoprocessamento.

O termo Geoprocessamento representa o conjunto das técnicas para coleta (Cartografia, Sensoriamento Remoto, GPS, Topografia, levantamento de dados alfanuméricos, etc.), armazenamento (Banco de Dados - Orientados a Objetos, Relacional, Hierárquico, etc.), tratamento e análise (como Modelagem de Dados, Geoestatística, Aritmética Lógica, funções topológicas) e uso integrado de informações espaciais, em Sistema de Informação Geográfica - SIG (FUJIHARA, 2002).

Já Câmara e Medeiros (1997), no tocante a sua aplicação, afirmam que o Geoprocessamento apresenta um enorme potencial, baseando-se em tecnologias de custo relativamente baixo, e atualmente tem se expandido de forma significativa a sua influência e aplicação na área de meio ambiente e análise de recursos naturais.

A Cartografia, a Topografia, o GPS e o Sensoriamento Remoto são ciências e técnicas que se relacionam com o geoprocessamento. O Sensoriamento Remoto agrega conhecimentos e técnicas utilizadas para a observação, análise, interpretação e gestão do espaço terrestre a partir de medidas adquiridas em plataformas aéreas, espaciais, terrestres ou marítimas. Esta ciência permite a interpretação visual dos dados (fotografias aéreas e imagens orbitais) sob forma digital ou analógica buscando a identificação de feições impressas nessas imagens e a determinação de seu significado.

O GPS é um sistema de navegação baseado em satélites destinado a obter coordenadas geográficas para identificação de eventos, sejam eles apenas uma localização pontual ou uma área. Para se obter tais pontos, há uma constelação de 24 satélites NAVSTAR, desenvolvidos pelo Departamento de Defesa dos EUA, que transmitem sinais que podem ser decodificados por receptores especialmente projetados para determinar, com precisão, pontos na superfície terrestre. Dependendo da acurácia do aparelho utilizado, podem-se obter poucos milímetros a metros de erro na precisão do ponto coletado. Segundo Duque e Mendes (2006), o receptor GPS precisa de, pelo menos, quatro satélites para a obtenção de uma posição fixa tridimensional, mas é desejável que este rastreie mais satélites simultaneamente, pois a movimentação destes faz com que os mesmos possam sair da órbita necessária para a captação dos dados pelo receptor. A maioria dos receptores consegue captar sinais de 08 a 12 satélites ao mesmo tempo (BERNARDI e LANDIM, 2002).

As informações adquiridas por ferramentas de sensoriamento remoto e GPS, assim como dados alfanuméricos e mapas vetoriais, são inseridas nos chamados Sistemas de Informação Geográfica - SIG. Estes sistemas têm como característica o armazenamento e a geração de produtos que servem de base para a análise espacial de dados geográficos.

Segundo Rocha (2000), com o SIG é possível armazenar e processar dados espaciais obtidos por fontes diversas (GPS, mapas existentes, sensoriamento remoto); além de recuperar e corrigir os dados processados de uma forma eficiente e dinâmica; permite alterar a forma

Geografia Ensino \& Pesquisa, v. 17, n. 2 p. 182-198, maio/ago. 2013

Costa, F. R.; Lima, R. F. S.; Silva. S. P. P

ISSN 2236-4994 I 187 
dos dados através de regras de agregação definidas pelo usuário, ou produzir estimativas de parâmetros e restrições para modelos de simulação (como a simulação de inundações) e gerar informações espaciais rápidas a partir de questionamentos sobre os dados e suas inter-relações e têm a capacidade para controlar a exibição e saída de dados em ambos os formatos (gráfico e tabular).

Dias et al. (2003) utilizam a ferramenta de Geoprocessamento para a construção de mapas temáticos relativos a áreas de inundação no Município de Volta Redonda - RJ, tendo como resultado a identificação e recomendação de procedimentos a serem adotados para distintas áreas, visando à ocupação ordenada do solo.

\section{Área de estudo}

A área de estudo, cidade de Pau dos Ferros - RN, localiza-se na Região denominada Alto Oeste Potiguar, entre as coordenadas geográficas: A latitude $6^{\circ} 14^{\prime} 18^{\prime \prime}$ sul e longitude $38^{\circ} 17^{\prime} 44^{\prime \prime}$ oeste; B latitude 5'59'00" sul e longitude 3801'26” oeste (Figura 2).

Figura 01- Localização da área em estudo.

Geografia Ensino \& Pesquisa, v. 17, n. 2 p. $182-198$, maio/ago. 2013

Carta de risco de inundação a partir de modelos srtm na área urbana de pau dos Ferros - RN

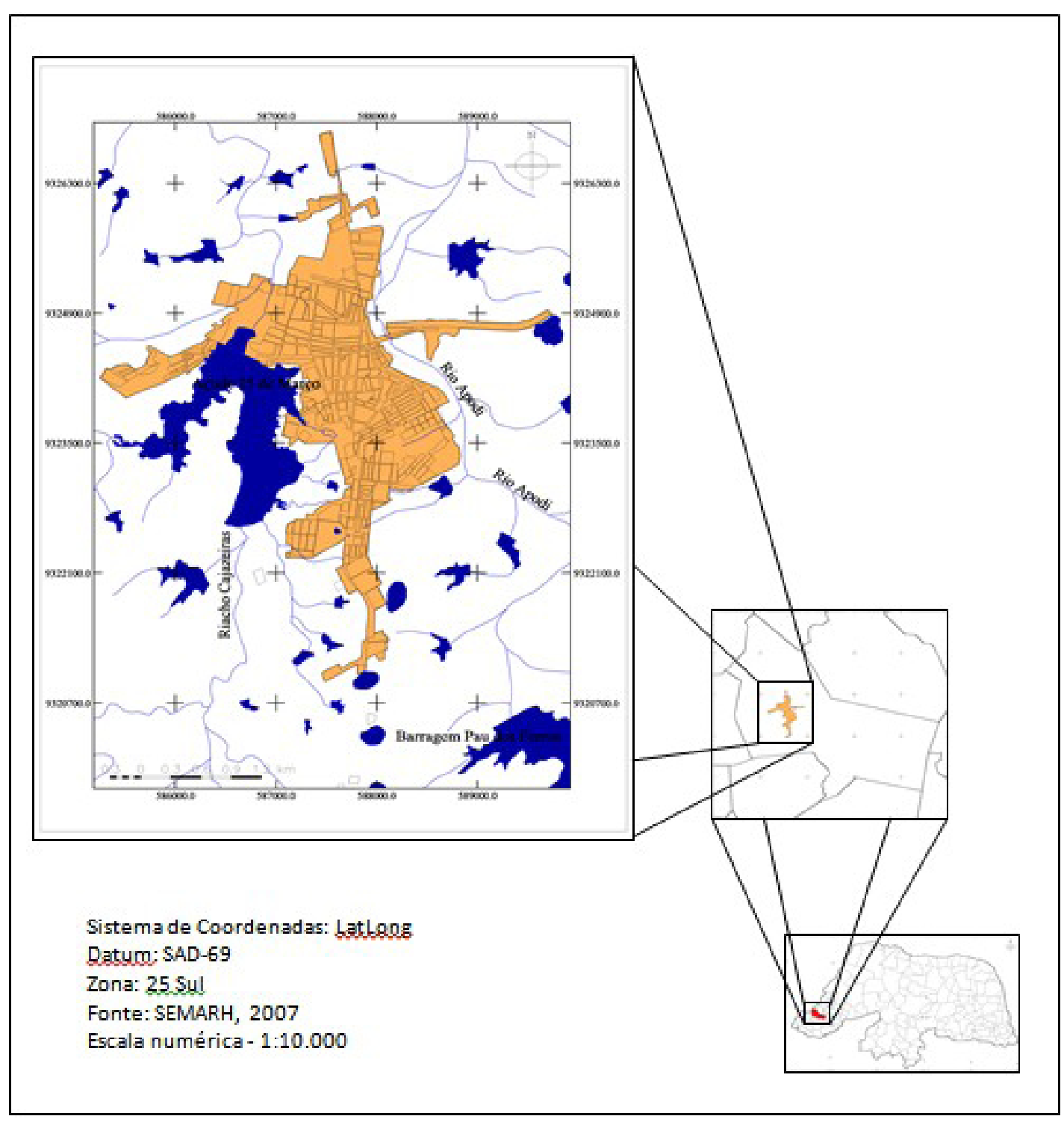




\section{Localização da área em estudo.}

Tem como característica principal ser o polo regional dos principais serviços públicos e privados disponíveis para atender aos demais municípios pertencentes à região. Está inserida na sua totalidade na bacia hidrográfica do rio Apodi, que será um dos rios contemplados com as águas da integração do rio São Francisco, a partir do eixo norte do projeto, que já se encontra em andamento.

O rio Apodi é o responsável pelo abastecimento de várias cidades da Região, e no caso especial da cidade de Pau dos Ferros, tem a barragem homônima à cidade como seu principal reservatório das águas represadas nos períodos chuvosos.

Além do rio Apodi, o seu afluente, riacho Cajazeiras, é responsável em abastecer outro importante corpo de água, o açude 25 de Março

Segundo IDEMA (2003), o município de Pau dos Ferros é caracterizado por um clima muito quente e semiárido, com estação chuvosa atrasando-se para o outono. a pluviometria anual é de aproximadamente $720 \mathrm{~mm}$, onde o período chuvoso aparece entre os meses de fevereiro a junho.

Em relação à temperatura anual, o município apresenta uma média de $28,1^{\circ} \mathrm{C}$, sendo a máxima de $36^{\circ} \mathrm{C}$ e a mínima de $21^{\circ} \mathrm{C}$. Já a umidade do ar no município está na média de $66 \%$, sendo o mês de abril o mais úmido, variando entre 70 e $80 \%$, e o mês de novembro o menos úmido, apresentando menos de 60\% (IDEMA, 2003).

A vegetação característica do município é a Caatinga Hiperxerófila - vegetação de caráter mais seco, com abundância de cactáceas e plantas de porte mais baixo e de baixa densidade. Entre outras espécies destacam-se a jurema-preta, mufumbo, faveleiro, marmeleiro, xiquexique e facheiro (IDEMA, 2003).

O município de Pau dos Ferros encontra-se inserido, geologicamente, na Província Borborema, sendo constituído pelos litotipos do Complexo Jaguaretama, das Suítes Poço da Cruz (PP3 pc) e Calcialcalina de Médio e Alto Potássio Itaporanga (NP3 2cm), da Formação Antenor Navarro (K1an) e pelos depósitos Colúvio-eluviais (NQc) (CPRM, 2005).

Geomorfologicamente predominam formas tabulares de relevos, de topo plano, com diferentes ordens de grandeza e de aprofundamento de drenagem, separados geralmente por vales de fundo plano (IDEMA, 2003).

O município de Pau dos Ferros é formado por três tipos de solos: argissolo vermelhoamarelo, luvissolo e chernossolo (CPRM, 2005). Dentre eles o predominante é o argissolo vermelho-amarelo. Segundo o IDEMA (2009), este tipo de solo possui fertilidade alta, textura média e média cascalhenta, acentuadamente drenado, relevo suave. Em relação ao uso, este tipo de solo é restrito a culturas resistentes à seca, recomendando o uso intensivo de práticas de controle de erosão.

\section{Áreas inundáveis na cidade de Pau dos Ferros - RN}

Historicamente, o processo de construção da cidade de Pau dos Ferros se deu próximo ao leito maior do rio Apodi, motivado por facilidades de transporte, uso da água para consumo e disposição de resíduos, assim como pela diminuição da sensação térmica de calor, uma vez que a cidade se encontra inserida na Região Semiárida Nordestina.

O resultado deste processo de ocupação mostra que, diferente de algumas cidades Geografia Ensino \& Pesquisa, v. 17, n.2 p. 182-198, maio/ago. 2013 brasileiras, Pau dos Ferros tem como alvo das inundações, não apenas a classe menos favorecida, mas também comerciantes, prefeitura e até algumas residências da classe média da cidade.

No período chuvoso, que geralmente ocorre nos períodos de janeiro a maio, alguns

Costa, F. R.; Lima, R. 
pontos da cidade inundam pela deficiência da drenagem urbana, assim como pela forma de ocupação historicamente realizada na cidade. $O$ resultado são residências e pontos comerciais inundados, além da dificuldade de acesso a diversas partes da cidade. Tais impactos geram perdas econômicas, além de prejudicar a realização de serviços que se encontram especificamente na área urbana central.

Pode-se dividir os bairros adjacentes aos corpos d'água que percorrem a cidade no sentido sul-norte (Cajazeiras e Apodi) (Figura 03). Além do centro da cidade, os bairros São Geraldo e Manoel Deodato sofrem com as águas advindas da cheia do rio Apodi, que tem seu volume aumentado a partir do transbordamento das águas da Barragem Pau dos Ferros, a montante da cidade.

Já pelo Riacho Cajazeiras, os bairros atingidos são Riacho do Meio, Nove de Janeiro, Paraíso e o São Judas Tadeu. Destes, os bairros Riacho do Meio e São Judas Tadeu são atingidos pelo transbordamento das águas do Açude 25 de Março nas porções oeste e leste, respectivamente; enquanto que os bairros Paraíso e Nove de Janeiro são afetados pelo transbordamento das águas do Açude na sua parte norte, onde deságua maior volume de água pós cheia (Figura 03).

Figura.03 - Carta de localização dos bairros em Pau dos Ferros - RN.

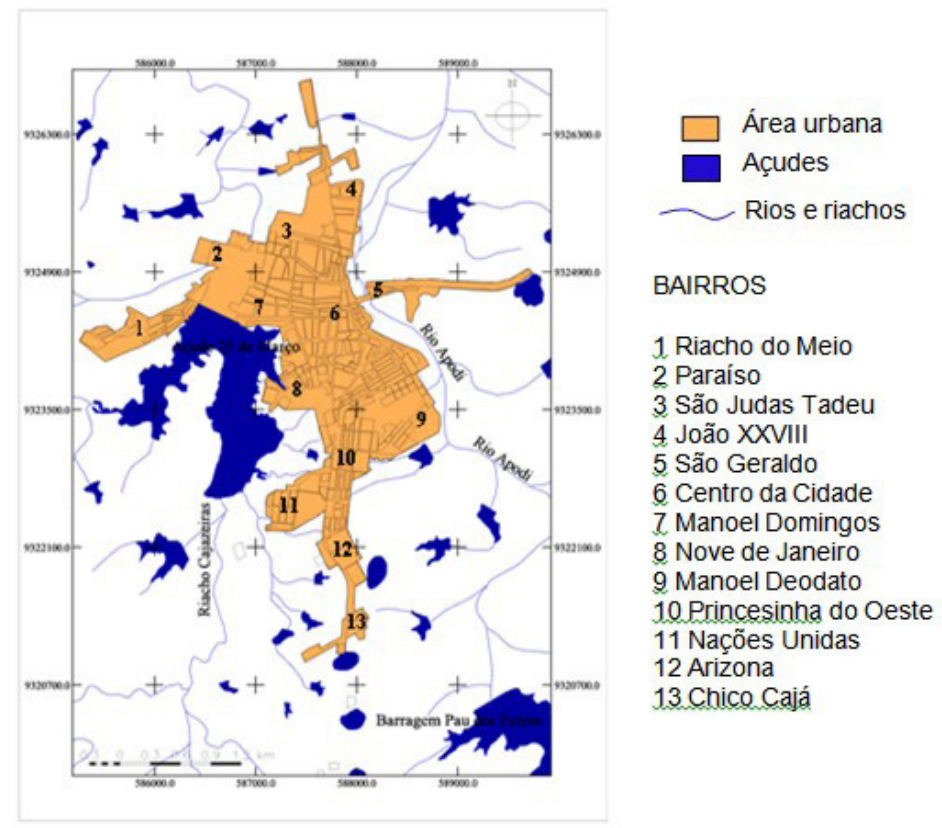

\section{Metodologia}

A modelagem e a implementação do banco de dados geográficos foram feitas no

Geografia Ensino \& Pesquisa, v. 17, n. 2 p. $182-198$, maio/ago. 2013

Carta de risco de inundação a partir de modelos srtm na área urbana de pau dos Ferros - RN

190 I ISSN 2236-4994 SIG-SPRING 5.1. Foram utilizados para a definição das áreas com riscos de inundação os modelos Shuttle Radar Topographic Mission - SRTM, assim como imagens do satélite CBERS 2B com instrumento imageador High Resolution Panchromatic Camera - HRC, uma câmera pancromática que possui uma resolução espacial de 2,7 metros, considerada de alta resolução, obtida em 11 de outubro de 2008, e fotografias aéreas do município obtidas em agosto de 1987 com escala de imageamento 1:17.000, além da base cartográfica da Secretaria de Estado do Meio Ambiente e Recursos Hídricos - SEMARH/RN na escala 1:100.000 e pontos obtidos em campo via aparelho GPS Etrex Venture. 
O SIG SPRING 5.1 foi utilizado para armazenar os dados obtidos, permitindo a realização do mosaico e georreferenciamento das imagens de satélite e fotografias aéreas. Juntamente com o tratamento digital das imagens, os trabalhos de reconhecimento de campo em algumas áreas do Rio Apodi permitiram resolver problemas relacionados ao processo de identificação de objetos geográficos observados nas imagens.

A imagem de satélite refere-se à órbita ponto 149_A/107_2 do sensor HRC do satélite CBERS 2B. Utilizou-se o sistema de projeção UTM, datum horizontal SAD-69, meridiano central $39^{\circ}$, hemisfério sul.

A modelagem incluiu a geração das categorias e modelos de dados do SPRING, conforme especificados na tabela 01 .

Tabela 01 - Organização das categorias utilizadas no trabalho.

\begin{tabular}{|c|c|c|c|}
\hline Cat. & Modelo de dados & Plano de informação & Classes \\
\hline Hidro & Cadastral & Hidro_cad & $\begin{array}{c}\text { Açude 25 de março; Barragem Pau } \\
\text { dos Ferros; Rios; Açudes }\end{array}$ \\
\hline Altimetria & MNT & Mapa Altimetria & $\begin{array}{c}\text { Amostras; Grade retangular; Grade } \\
\text { SRTM }\end{array}$ \\
\hline Local & Cadastral & Limites & $\begin{array}{c}\text { Limite municipal Pau dos Ferros; } \\
\text { Localidades menores }\end{array}$ \\
\hline Pontos GPS & MNT & Pontos GPS & Mapa pontos GPS \\
\hline Imagem & Imagem & Imagem & $\begin{array}{c}\text { CBERS 2B HRC 2008; Fotos aéreas } \\
\text { 1987; Imagem SRTM }\end{array}$ \\
\hline Área urbana & Cadastral & $\begin{array}{c}\text { Mapa da área urbana 1987; } \\
\text { Mapa da área urbana 2008 }\end{array}$ & \begin{tabular}{c} 
Arbana \\
\hline Inundação
\end{tabular} \\
\hline Temático & Mapa risco de inundação & $\begin{array}{c}\text { Inundação Rio Apodi; Inundação } \\
\text { Riacho Cajazeiras }\end{array}$ \\
\hline
\end{tabular}

Os dados obtidos na SEMARH - RN na escala 1:100.000, relativos as informações hídricas da área em estudo, assim como a altimetria e os limites municipais, foram importados no formato de arquivo shapefile e transformados para o formato *.spg, sendo esta a extensão de arquivo reconhecido pelo software SPRING.

Importaram-se também as imagens de satélite, a partir da extensão do SPRING responsável pela conversão de dados raster, o IMPIMA, onde foram transformados do formato *.tiff para o formato *.spg. As fotografias aéreas ortorretificadas, foram escaneadas e salvas na extensão de arquivo *.tiff para ser reconhecido no programa IMPIMA. A imagem de satélite já georreferenciada foi importada diretamente e as fotografias aéreas foram georreferenciadas a partir da ferramenta de registro existente na parte de edição do software, para que, posteriormente, pudessem ser trabalhadas.

A vetorização da área urbana da cidade de Pau dos Ferros foi realizada a partir da imagem CBERS 2B, abrangendo quase a totalidade da cidade. A cobertura por nuvens de uma pequena parte da cidade dificultou sua identificação. A solução para este problema foi a identificação e coleta de pontos em campo com GPS com uma precisão de aproximadamente 07 metros. Além da área urbana, foram realizadas correções e melhorias na vetorização da hidrografia local, pois seriam os vetores necessários para se delimitar as áreas com possíveis riscos de inundação na cidade.

Para a identificação do curso do rio Apodi e suas possíveis áreas de inundação foram realizadas análises visuais das imagens do sensor SRTM, utilizando o realce de contraste do

Geografia Ensino \& Pesquisa, v. 17, n. 2 p. $182-198$, maio/ago. 2013

Costa, F. R.; Lima, R. F. S.; Silva. S. P. P

ISSN 2236-4994 
SPRING para melhor observar as feições do curso dos rio Apodi e riacho Cajazeiras.

Após esta identificação, utilizando-se da ferramenta palheta de cores do software SPRING 5.1, foi elaborada uma codificação das faixas hipsométricas a partir da inserção de falsas cores na imagem SRTM, cuja principal característica é a obtenção de cotas altimétricas. As imagens foram geradas por classes de altitude $(\mathrm{m})$, com geração de faixas hipsométricas de $20 \mathrm{em} 20$ metros, a partir das quais foi realizado o processo de fatiamento.

Posteriormente foi realizada a importação do fatiamento para a categoria temática. Em seguida, foi realizada a suavização dos vetores para retirar algumas distorções geradas pelo processo automatizado da extração das isolinhas obtidas a partir da modelo SRTM. O próximo passo foi gerar classes temáticas (baixo, médio e alto)para a identificação das áreas mais susceptíveis à inundação, tendo como referência a altitude e a proximidade dos cursos de água, ou onde os mais próximos ao leito maior possuem maiores riscos (alto) e os mais distantes menores riscos (baixo).

Em seguida, buscou-se os pontos considerados inundáveis, a partir da obtenção das coordenadas dos pontos em campo com uso do GPS. Estes pontos encontram-se identificados a partir de letras na figura 3 para facilitar a sua localização.

Mesmo com baixa precisão cartográfica, devido a escala de produtos utilizados para a realização do recorte hipsométrico de 20 em 20 metros foi útil pois, segundo Valeriano (2004), grande parte do território nacional é desprovido de mapeamento em escalas adequadas para análises sobre informações topográficas. Por este aspecto, pode-se considerar a imagem SRTM a melhor informação topográfica já disponibilizada para grande parte do território brasileiro com limitação de escala de precisão, com 90 metros de resolução espacial da SRTM.

Barros et al (2005) afirmaram, ainda que em andamento, que, os DEMs gerados pelo SRTM, apresentaram-se consistentes para diversas aplicações, em especial para locais onde não se dispunha de dados em escala maior.

Já Santos et al (2006) afirmam que para a escala de 1:100.000, a utilização dos modelos SRTM para áreas com características de baixa variação de altitude se mostram satisfatórias, a partir de um maior tratamento estatístico aplicado a análise dos resultados.

No presente trabalho, a área inundável possui pouca variação altimétrica, o que dificultou demonstrar, com exatidão, as áreas inundáveis, pois a imagem com melhor resolução que dispúnhamos possui escala 1: 18.000, referente a fotografias aéreas datadas de 1987.

\section{Discussão de resultados}

$\mathrm{Na}$ figura 03, percebe-se que, nas proximidades do leito do rio Apodi, além do centro da cidade, os bairros São Geraldo e Manoel Deodato sofrem com as águas advindas da cheia do rio, que tem seu volume aumentado a partir do transbordamento das águas da Barragem Pau dos Ferros, a montante da cidade.

$\mathrm{Na}$ implantação do Projeto de Integração do rio São Francisco às bacias do Nordeste Setentrional, a Bacia Hidrográfica do Rio Apodi será contemplada a partir do Eixo Norte do projeto, já em andamento. Um dos resultados deste projeto será a perenização do rio Apodi.

Geografia Ensino \& Pesquisa, v. 17, n.2 p. 182-198, maio/ago. 2013

Carta de risco de inundação a partir de modelos srtm na área urbana de pau dos Ferros - RN

192 I ISSN 2236-4994
Com isso, no período chuvoso, entre os meses de janeiro a maio, deverá ocorrer um aumento no volume das águas do rio, com consequentes inundações de áreas que anteriormente não sofriam tais impactos.

Ao longo do trecho do rio Apodi e do riacho Cajazeiras, alguns pontos merecem destaque, uma vez que se apresentam com alto grau de risco de inundação, como pode ser visto na tabela 02 .

No bairro Manoel Deodato, os pontos A e B estão localizados em áreas de expansão na 
zona periférica da cidade. Ainda que pouco urbanizada, é necessário planejamento na forma de ocupação desta área, por ser propícia a inundações repentinas durante o período chuvoso, variando o risco de ocorrência de médio a alto.

Os pontos C e D localizam-se no Centro da cidade. São considerados pontos críticos, com médio (C) e alto (D) risco de inundações, pois esta área da cidade encontra-se nas cotas altimétricas mais baixas, além de estar próxima ao leito menor do rio Apodi. Anualmente, parte desta área sofre com o avanço das águas do rio, assim como na deficiência da drenagem pluvial.

Figura 03 - Carta das áreas e pontos com risco de inundação na cidade de Pau dos Ferros - RN.

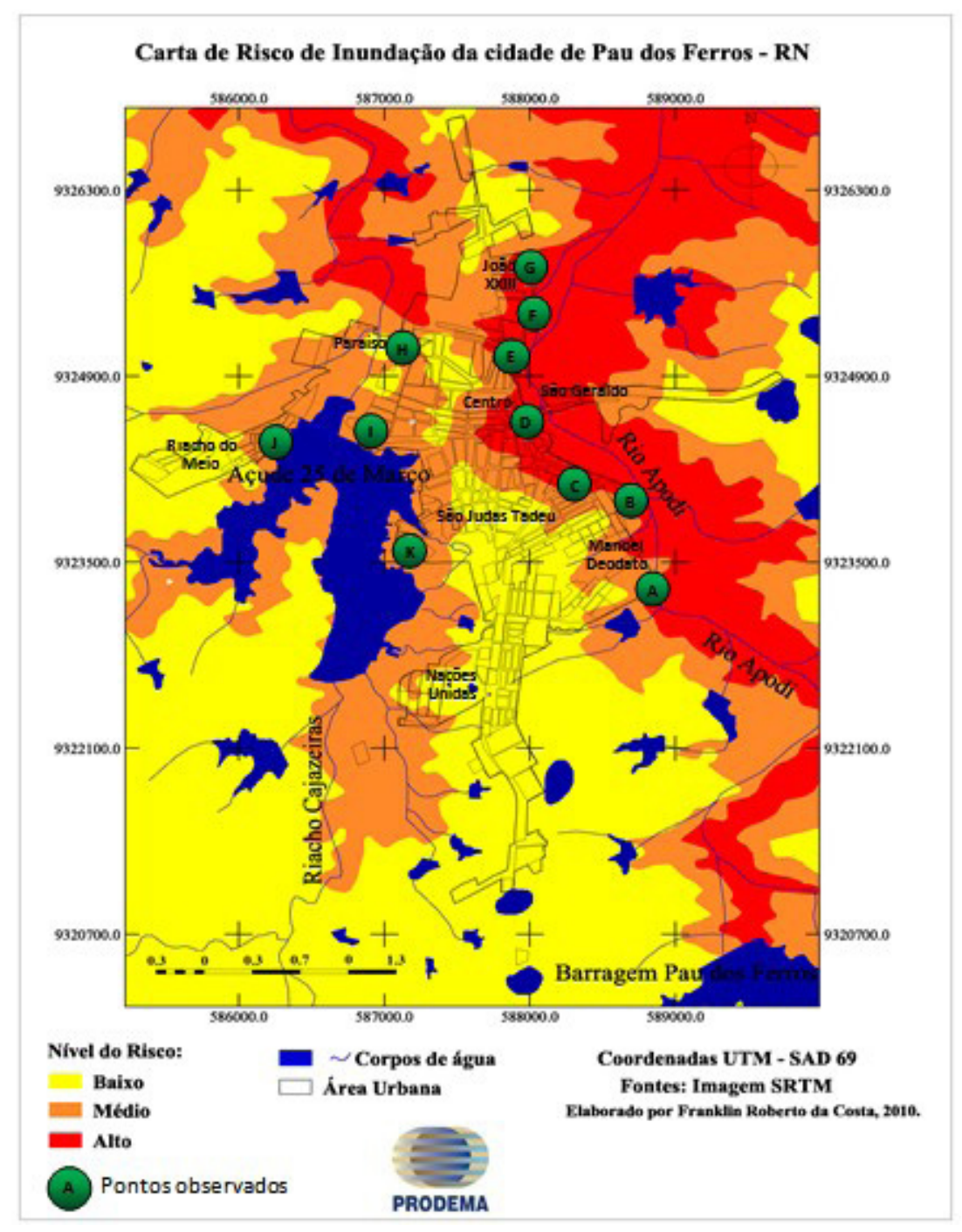

O bairro João XXIII é considerado um dos mais recentes da cidade de Pau dos Ferros e localiza-se na zona periférica da porção norte da cidade. Neste bairro foram construídas residências, fábricas, marcenarias e uma das principais escolas privadas de nível fundamental e médio da região. É necessário atenção em parte deste bairro pois está localizado em uma área que varia do grau baixo ao alto de ocorrências de inundações (pontos E, F e G).

O ponto H está localizado no bairro Paraíso. Assim como o João XVIII, este bairro está em processo de expansão na cidade e se caracteriza pela forma desordenada de ocupação, atendendo a população de diferentes classes sociais. Neste local, o agente causador das

Geografia Ensino \& Pesquisa, v. 17, n.2 p. 182-198, maio/ago. 2013

Costa, F. R.; Lima, R. F. S.; Silva. S. P. P

ISSN 2236-4994 
inundações é o Riacho Cajazeiras. O impacto nesta área se dá pelo transbordamento das águas do Açude 25 de Março, pois o bairro localiza-se a jusante do açude.

A atenção nesta parte da cidade é importante, pois mais a montante, o bairro Nações Unidas está em processo de crescimento acelerado, e vem gerando a impermeabilização do solo, o desmatamento das matas ciliares e o aterramento de lagoas. Estes fatores devem contribuir para o aumento no volume das águas que convergem para o açude, com consequente transbordamento acima da média, gerando uma dispersão das águas em partes do bairro Paraíso que anteriormente não sofria com este tipo de impacto ambiental.

Os bairros de Nove de Janeiro e Riacho do Meio, onde estão localizados os pontos I e J apresentam risco médio de inundação nas proximidades da parede do açude 25 de Março, pois algumas drenagens ficam represadas e terminam se acumulando nas ruas próximas. Existe também uma segunda sangria do açude no ponto J, inserido no bairro Riacho do Meio.

Tabela 02 - Identificação das áreas com diferentes graus de risco de inundações.

\begin{tabular}{|c|c|c|c|}
\hline Ponto & Bairro & Rio influente & Graus de risco \\
\hline A & Manoel Deodato & Apodi & Alto e Médio \\
\hline B & Manoel Deodato & Apodi & Alto e Médio \\
\hline C & Centro & Apodi & Alto e Médio \\
\hline D & Centro & Apodi & Alto e Médio \\
\hline E & João XXIII & Apodi & Alto e Médio \\
\hline F & João XXIII & Apodi & Alto e Médio \\
\hline G & João XXIII & Apodi & Médio \\
\hline H & Paraíso & Cajazeiras & Médio e Baixo \\
\hline I & Nove de Janeiro & Cajazeiras & Médio \\
\hline J & Riacho do Meio & Cajazeiras & Médio \\
\hline K & São Judas Tadeu & Cajazeiras & Médio \\
\hline
\end{tabular}

O ponto $\mathrm{K}$, assim como o ponto I, aparece nas proximidades da parede do açude 25 de Março e sofre com a deficiência na drenagem pluvial e no transbordamento do açude, quando o mesmo chega ao seu volume máximo de suporte, inundando ao seu redor. Paredes de contenção foram construídas no bairro São Judas Tadeu pela prefeitura local com vistas a reduzir este problema. Como contra-senso, estão sendo construídas casas populares próximas a esta área, que poderão, em um futuro próximo sofrer inundações, por estarem localizadas em área de médio risco.

Geografia Ensino \& Pesquisa, v. 17, n.2 p. 182-198, maio/ago. 2013

Carta de risco de inundação a partir de modelos srtm na área urbana de pau dos Ferros - RN

194 I ISSN 2236-4994

\section{Considerações finais}

O nível de análise e os dados utilizados, permitiu associar o uso de Geotecnologias para a identificação das áreas de risco de inundação, com dados obtidos via coleta em campo para a geração da carta de risco de inundação na cidade de Pau dos Ferros. As áreas com altos riscos de inundações estão localizadas nas proximidades do leito maior do Rio Apodi e nas paredes do açude 25 de Março. O ineficiente sistema da drenagem urbana, aliado ao processo de perenização do rio pelo projeto de integração da Bacia do São Francisco com as Bacias do 
Nordeste Setentrional poderão contribuir para a ampliação das áreas de inundação na cidade de Pau dos Ferros - RN.

O trabalho identificou as principais áreas de risco de inundação, definindo graus que variaram do baixo ao alto e apontando os bairros que poderão sofrer impactos oriundos da elevação do nível das águas no período chuvoso na região.

Espera-se que a metodologia adotada sirva de contribuição para o planejamento da ocupação urbana da cidade de Pau dos Ferros, que assim como muitas cidades do semiárido nordestino, enfrenta um crescimento acelerado e desordenado, associado a um processo de expansão e adensamento urbano que poderão causar impactos ambientais irreversíveis no futuro.

Além disso, é necessário um estudo mais acurado desta pesquisa, a partir da identificação do perfil topográfico em uma escala maior, para podermos identificar, com mais precisão, as áreas susceptíveis a inundações na cidade, para que sirva de subsidio na elaboração de estudos locais e no planejamento e execução de serviços públicos de primeira necessidade, como habitação e transporte.

\section{Agradecimentos}

Agradecimentos à Universidade do Estado do Rio Grande do Norte, pela bolsa de incentivo à capacitação docente oferecida para a realização do Mestrado em Natal - RN, aos membros do Núcleo de Estudos Geoambientais e Cartográficos da UERN - Campus Pau dos Ferros, pelo auxílio na coleta de dados e informações e ao Programa de Pós-graduação em Desenvolvimento e Meio Ambiente - PRODEMA/UFRN.

\section{Referências}

AGÊNCIA NACIONAL DAS ÁGUAS - ANA. Conjuntura dos recursos hídricos no Brasil. Disponível em http://conjuntura.ana.gov.br/. Acesso em março 2009.

ANTUNES, M.L.S.; BARROS, A.M.A. Condições pluviométricas e risco ambiental no município de Porciúncula - RJ. V Seminário Internacional de Defesa Civil, São Paulo, Brasil. Anais...18-20 nov. 2009, s/p.

BARROS, R.S. et al. Avaliação do modelo digital de elevação do SRTM na ortorretificação de imagens Landsat 7 - Área de aplicação: Angra dos Reis - RJ. In: XII Simpósio Brasileiro de Sensoriamento Remoto, Goiânia, Brasil. Anais... 16-21 abril 2005, INPE, p. 3997-4004.

BERNARDI, J.V.E. \& LANDIM, P.M.B. Aplicação do Sistema de Posicionamento Global (GPS) na coleta de dados. DGA,IGCE,UNESP/Rio Claro, Lab. Geomatemática,Texto Didático 10, 31 pp. 2002. Disponível em: <http://www.rc.unesp.br/igce/aplicada/textodi. html>. Acesso em: 10/08/2010.

BRIGUENTI, E.C.; CARPI JR. S.; DAGNINO, R.S. Identificação de riscos hidrogeomorfológicos em unidades geossistêmicas da bacia do ribeirão das Anhumas,

Geografia Ensino \& Pesquisa, v. 17, n.2 p. 182-198, maio/ago. 2013

Costa, F. R.; Lima, R. F. S.; Silva. S. P. P

ISSN 2236-4994 
Campinas/SP. In: XII Simpósio Brasileiro de Geografia Física Aplicada, 2007, Natal. Anais... Natal: DGE/UFRN, 2007. 20p. (CD-ROM)

CÂMARA,G.; MEDEIROS, J.S. Princípios Básicos do Geoprocessamento. In: Assad, E.; Sano, E.E.(eds.), Sistema de Informações Geográficas. Aplicações na Agricultura. Brasília, DF, EMBRAPA., 1997 (2a. edição, revista e ampliada).

CPRM - Serviço Geológico do Brasil. Projeto cadastro de fontes de abastecimento por água subterrânea. Diagnóstico do município de Pau dos Ferros, Estado do Rio Grande do Norte. Organizado [por] João de Castro Mascarenhas, Breno Augusto Beltrão, Luiz Carlos de Souza Junior, Saulo de Tarso Monteiro Pires, Dunaldson Eliezer Guedes Alcoforado da Rocha, Valdecílio Galvão Duarte de Carvalho. Recife: CPRM/PRODEEM, 2005.

DAVIS JR., C. A., FONSECA, F. T. Introdução aos sistemas de informações geográficas. [s.n]: Belo Horizonte, 2003.

DIAS, J. E.; GOES, M. H. D. B. e GOMES, O. V. D. O. Áreas de riscos de enchentes no município de Volta Redonda: uma aplicação por geoprocessamento. In: Caminhos de Geografia. Uberlândia - MG, v.2, n.10, p.013-025, set 2003.

DUQUE, R. C.; MENDES, C. L. O planejamento turístico e a cartografia. Campinas - SP: Editora Alínea, 2006. 92p.

ENOMOTO, C.F. Método para elaboração de mapas de inundação: estudo de caso para a Bacia do Palmital, Paraná. Curitiba: UFPR, 2004.132p. Dissertação (Mestrado), UFPR.

FUJIHARA, A.K. Predição de erosão e capacidade de uso do solo numa microbacia do oeste paulista com suporte de geoprocessamento. Piracicaba, SP: USP, 2002. Originalmente apresentada como dissertação de mestrado, Escola Superior de Agricultura "Luiz de Queiroz", Universidade de São Paulo, 2002. p. 135.

GROSTEIN, M. D. Metrópole e expansão urbana: a persistência de processos “insustentáveis”. São Paulo em Perspectiva, jan./mar. 2001, vol.15, no.1, p.13-19.

INSTITUTO DE DESENVOLVIMENTO ECONÔMICO E DO MEIO AMBIENTE DO RIO GRANDE DO NORTE - IDEMA. Perfil do seu município. Natal - RN. 2003. Disponível em: www.idema.rn.gov.br. Acesso em maio de 2009.

ISDR (INTERNACIONAL STRATEGY FOR DISASTER REDUCTION). Living with risk. A Global review of disaster reduction initiatives. United Nations, Inter-Agency Secretariat. ISDR Secretariat. Preliminary Version. Geneva, Switzerland, 2002.384p.

JESUS, J. A. Simulação de inundações urbanas com imagens CBERS, DEM SRTM e levantamentos GPS - Estudo de caso na cidade de Jacobina, BA. In: Simpósio Brasileiro de Sensoriamento Remoto, XIII, 2007, Florianópolis. Anais...Florianópolis: INPE, 2007, p. $929-937$.

Geografia Ensino \& Pesquisa, v. 17, n. 2 p. $182-198$, maio/ago. 2013

Carta de risco de inundação a partir de modelos srtm na área urbana de pau dos Ferros - RN

196 I ISSN 2236-4994
NEVES, K. B. L. Avaliação da relação entre doenças hídricas e inundações por meio de imagens de radar Jers-1: estudo de caso: Bacia do Rio Madeira, Rondônia. Rio de Janeiro: UFRJ, 2005. 160p.

PEDRON, F.A.; DALMOLIN, R.S.D.; AZEVEDO, A.C.; BOTELHO, M.R.; ROSA, A.S. Análise da dinâmica especial da ocupação das terras e seus conflitos de uso no perímetro urbano de Santa Maria - RS (1975 - 2002). In: Ciência Rural, Santa Maria, v.36, n.6, 2006. 
PEREIRA E SILVA, L. Modelagem e geoprocessamento na identificação de áreas com risco de inundação e erosão na bacia do rio Cuiá. João Pessoa, Paraíba: UFPB, 2007.118p. Dissertação (Mestrado), UFPB.

PEREIRA FILHO, A.J.; HALLAK, R.; BARROS, M.T.L.; Aspectos socioeconômicos e hidrometeorológicos das enchentes na região metropolitana de São Paulo no período de 2000 a 2004. In: SIMPÓSIO BRASILEIRO DE DESASTRES NATURAIS, 1., 2004, Florianópolis. Anais...Florianópolis: GEDN/UFSC, 2004, p.633-642. (CD-ROM)

ROCHA, C.H.B. Geoprocessamento: tecnologia transdisciplinar. Juiz de Fora: o autor, 2000. $220 \mathrm{p}$.

ROCHA, JOÃO SOROMENHO, (1995) - Prevenção de inundações e reabilitação de edifícios em zonas inundáveis. In: Revista Territorium, Coimbra, pp. 11-19.

SANTOS, P.R.A. et al. Avaliação da precisão vertical dos modelos SRTM para a Amazônia. In: Revista Brasileira de Cartografia. Rio de Janeiro - RJ, n.58/01, p.101-107, abr. 2006.

SATHLER, D. R. As redes para além dos rios: urbanização e desequilíbrios na Amazônia brasileira. (Tese de doutorado) Universidade Federal de Minas Gerais - MG: UFMG/ CEDEPLAR, 2009.

SECRETARIA DE RECURSOS HÍDRICOS DO RIO GRANDE DO NORTE - SERHID. Bacia hidrográfica do rio apodi. Disponível em: www.serhid.rn.gov.br. Acesso em ago. 2007.

SILVA, A. P. M.; BARBOSA, A. A. Validação da função mancha de inundação do SPRING. In: XIII Simpósio Brasileiro de Sensoriamento Remoto. Anais...Florianópolis, Brasil, 21-26 abril 2007, INPE, p. 5499-5505

SILVA, D.F.; SOUSA, F.A.S.; KAYANO, M.T. et al. Acompanhamento climático das bacias hidrográficas do rio Mundaú (AL e PE) e do rio Paraíba (PB). In: Revista Engenharia Ambiental. Espírito Santo do Pinhal, v.5, n.3, p.079-093, set/dez 2008.

SILVEIRA, W.N.; KOBIYAMA, M. Histórico de inundação em Joinville/SC - Brasil, no período de 1851-2007. In XVII Simpósio Brasileiro de Recursos Hídricos, 2007, São Paulo. Anais...São Paulo: ABRH, 2007. 16p. (CD-ROM).

TUCCI, C.M.; BERTONI, J.C. Inundações urbanas na América do Sul. Porto Alegre: Associação Brasileira de Recursos Hídricos, 2003a. 156p.

Gerenciamento Integrado de Inundações Urbanas no Brasil. In: Revista de Gestão da Água na América Latina, Vol.1, nº 1, jan/jun/2004.

Gestão das inundações urbanas. Apostila para o curso de Gestão das inundações urbanas. Porto Alegre, 2005. 197p.

VALERIANO, M. M. Modelo digital de elevação com dados SRTM disponíveis para a América do Sul. São José dos Campos, São Paulo: INPE, 2004. Disponível em:http:// www.ecologia.ufrgs.br/labgeo/downloads/SRTM/publicacao.pdf. Acesso em: julho de 2009.

ZHOURI, Andréa; OLIVEIRA, Raquel. Industrial landscapes and the uprooting of local populations: social and environmental conflicts in hydroelectric projects.2006.

Geografia Ensino \& Pesquisa, v. 17, n. 2 p. $182-198$, maio/ago. 2013

Costa, F. R.; Lima, R F. S.; Silva. S. P. P 


\section{Correspondência:}

Franklin Roberto da Costa - Universidade do Estado do Rio Grande do Norte/ CAMEAM/ UERN. BR 405 sem número. Bairro Arizona - Pau dos Ferros, RN. CEP: 59.900-000

E-mail: cassiane.victoria@gmail.com

Recebido em 08 de maio de 2012.

Revisado pelo autor em 15 janeiro de 2013.

Aceito para publicação em 15 de fevereiro de 2013. 